\title{
Simulation of whipping response of a large container ship fitted with a linear generator on board in irregular head seas
}

\author{
Yuxiao Cheng ${ }^{1} \cdot$ Tetsuo Okada $^{2} \cdot$ Hiroaki Kobayakawa $^{3} \cdot$ Tetsuji Miyashita $^{4} \cdot$ Tomoki Nagashima $^{3} \cdot$ Isao Neki $^{5}$
}

Received: Accepted:

CJASNAOE

\begin{abstract}
There is plenty of energy contained in the ocean waves, and great efforts have been made over recent decades, to make full use of these sustainable energy resources. As a novel device to utilize ocean wave energy, the authors propose in this paper a whipping energy converter, which utilizes a linear generator extracting power from ship's whipping and springing (hull girder 2-node vibration) responses. The device is designed resonant to the hull girder 2-node vibration frequency. Numerical simulation of the responses of the whipping energy converter was carried out under irregular head sea condition, using time domain ship motion analysis by Rankine source method and subsequent 3-dimensional whole ship FE analysis, and the main parameters of the whipping energy converter was studied. A 14,000 TEU large container ship was utilized in this study, because large container ship is prone to constant whipping and springing responses in real seas. As a result, it was found that the whipping energy converter can effectively generate power from the whipping and springing responses, and at the same time, the whipping energy converter functions as a dynamic damper. With the piston weight of 5 10 tons, the whipping vibration is visibly reduced, while if the piston weight is about 100 tons, the spectral peak is reduced to less than one-third. This implies that the whipping energy converter contributes to the prevention of fatigue damage due to whipping and springing, which is an
\end{abstract}

\section{T. Okada}

okada-t@ynu.ac.jp

${ }^{1}$ School of Naval Architecture, Ocean \& Civil Engineering, Shanghai Jiao Tong University, Shanghai, China (Yokohama National University at the time of study)

${ }^{2}$ Faculty of Engineering, Yokohama National University, Yokohama, Japan

${ }^{3}$ Offshore and Engineering Division, Japan Marine United Corporation, Tokyo, Japan

${ }^{4}$ Technical Research Center, Japan Marine United Corporation, Tsu, Japan

${ }^{5}$ IEM Co., Ltd., Kure, Japan imminent concern in the design of large container ships. It was also found that larger power generation can be expected as the piston weight is heavier, and the bow is the most effective location for this device.

Keywords Linear generator - Whipping energy converter • Whipping $\cdot$ Springing $\cdot$ Container ship $\cdot$ Rankine source method

\section{Introduction}

There is plenty of energy contained in the ocean waves. As Falcao [1] made a comprehensive review, great efforts have been made on wave energy utilization over recent decades, adopting wide variety of different technologies as to working principle, location, power take-off mechanism, etc. Early applications were mostly based on OWC (Oscillating Water Column) principle, where oscillating motion of the water free surface in a duct makes the trapped air inside the duct to flow through a turbine. One example of a floating OWC converter application can be seen in the "Mighty Whale" [2], whose full-sized prototype was deployed at the mouth of Gokasho Bay in Mie Prefecture, Japan and tested for several years. Another relatively new promising technology is the oscillating body system, where power is extracted from wave induced body motion, either floating or fully submerged. Ivanova et al. [3] used a fixed direct drive permanent magnet linear generator buoy to convert wave energy to electric power. Gao et al. [4] used a total floating energy converter which used the relative motion between the buoy and the inner body to generate power. Both of these two devices used wave periodic motion to drive the internal structure movement cutting magnetic induction line, which generated the current in the coil so that the energy of wave periodic motion was converted into electric energy.

All these wave energy utilization devices, which are meant to be deployed at a specific location of the ocean either near-shore or offshore, confronted many problems to hinder its full-scale realization, such as access for maintenance, need of long underwater electrical cables to supply power onshore and high initial cost. In this context, Minoura et al. [5] developed a novel power generation system, recovering energy from the ship motion induced by the encountering waves, where many advantages are 
expected as follows. Firstly, the ship body can replace the main oscillating body. Secondly, the generator facilities can be easily accessible on board. Moreover, the generated power can be effectively consumed on board the ship. They studied a linear generator contained in a marine container loaded at the bow, effectively extracting power from mainly pitch motion of the ship.

To effectively utilize wave energy by optimal wave energy absorption, it is essential to realize some kind of resonance of the oscillating body and the incident waves. This implies the following two difficulties:

(1) Considering relatively long period of the ocean waves, the oscillating body must be quite large, hindering step-by-step development using small-scale prototype.

(2) Actual ocean waves are irregular containing wide range of frequencies, and are not single-frequency.

As a novel device free from these difficulties, the authors propose in this paper a linear generator extracting power from ship's whipping and springing (hull girder 2-node vibration) responses. Container ships are becoming larger and larger due to the worldwide expansion of economy, and thus, it is concerned that the whipping and springing responses may increase due to the relatively smaller hull girder rigidity compared with smaller ships, causing adverse effect to fatigue strength as well as ultimate strength of the ship's hull girder. In fact, significant hull girder vibratory responses have been clearly noticed in the full-scale measurement of large container ships since more than a decade ago [e.g. 6, 7]. If these vibratory responses can be utilized to extract power, the aforementioned difficulties can be resolved as follows:

(1) Natural frequency of hull girder 2-node vibration of a large container ship is around $0.5 \mathrm{~Hz}$, while frequencies of ocean waves are around $0.05 \sim 0.2 \mathrm{~Hz}$. Because of this relatively high frequency, resonant condition can be more easily achieved with smaller devices.

(2) Frequency of the whipping and springing is almost constant, i.e. natural frequency of hull girder 2-node vibration, and variate only a little according to the different loading conditions of the ship. This also helps efficient design of the resonant body.

In addition to the resolution of these two difficulties, we can expect the following third benefit. When the linear generator to extract the whipping energy is composed of mass and spring system, the generator may function as a dynamic damper and mitigate the adverse effect of the whipping and springing to the structural strength. In this paper, as a preliminary study to develop whipping energy converter, time domain analysis of the elastic responses of a 14,000TEU large container ship with a linear generator is conducted, and the main parameters of the linear generator have been studied. Then, the effect of resonance condition, piston weight and the location of the device is discussed.

\section{Analysis methodologies and procedures}

\subsection{Time domain ship motion and elastic response analysis}

The analysis procedure as explained in the authors' previous papers [8-11] was applied in this paper. Firstly, Rankine source method is utilized to analyse time domain ship motion and wave pressure on the hull surface in a numerical tank simulating long-crested irregular head seas. The irregular wave train was generated according to ISSC1964 wave spectrum. The hull surface panel model used in the analysis, comprising 561 panels, is shown in Fig. 1. Time series of the wave variable pressure are obtained consistently using Bernoulli's equation in this procedure.

Subsequently, the obtained time domain hull inertia forces and the wave pressure were applied to 3-dimensional whole ship FE model of the ship, and elastic responses of all over the hull structures were analysed using Newmark- $\beta$ method. The whole ship FE model, consisting of 26,035 elements and 14,893 nodes, is shown in Fig. 2. Adopting the half breadth model, symmetry boundary conditions are applied along the centreline section. 3-DOF rigid body motion (surge, heave and pitch) is not constrained, but global equilibrium is assured by application of inertial forces all over the model cancelling the acting forces and moments. Rayleigh damping was applied with $\alpha=0.0$ and $\beta=$ 0.012 .

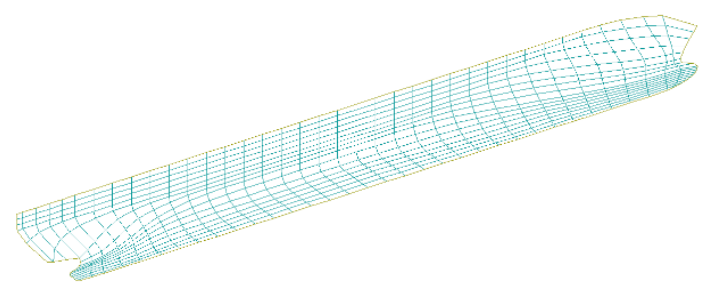

Fig. 1: Hull surface panel model

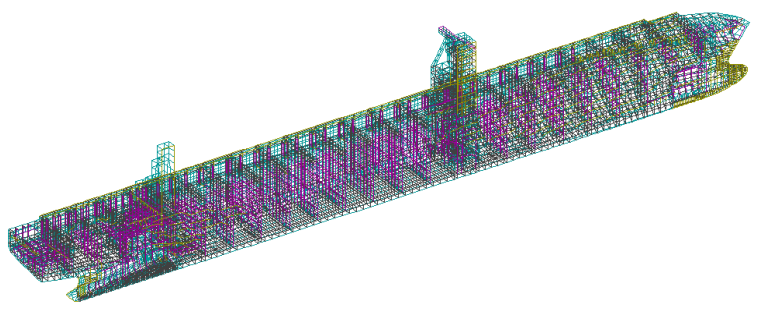

Fig. 2: 3-dimensional whole ship FE model

Table 1 shows the principal dimensions of the ship and the analysis parameters in this study. The numerical tank has the length of about $4.4 \mathrm{~km}$. The ship starts from one end of the tank and accelerates to achieve the target ship speed, while the irregular waves are generated from the other end of the tank. In this condition, the results of the last 4,096 steps after the ship encountered the waves among the total 7,279 calculated steps were considered to be valid, corresponding to about 5-minute run. The analyses in the following chapters are based on the data of this 5-minute run of the ship. This simulation of 7,279 steps takes about 10 days of computing using a computer with 2 CPUs (Xeon E5-2650v3, 2.3 GHz, 10 Core, $25 \mathrm{M}$ Cache), and in this study only the results of one run is available. Because this duration period of the simulation is considered to be insufficient to obtain statistically significant results, it is an important future task to carry out simulation with longer duration.

The wave period of $15 \mathrm{~s}$ corresponds to the wave length of 351 $\mathrm{m}$, which is comparable to the ship length. Therefore, in order to make the irregular wave prone to whipping, mean wave period of $15 \mathrm{~s}$ and significant wave height of $5 \mathrm{~m}$ were selected for this 
simulation.

Table 1 Principal dimensions and analysis parameters

\begin{tabular}{|l|c|}
\hline$L_{O A}$ & About $364 \mathrm{~m}$ \\
\hline$B$ & $50.6 \mathrm{~m}$ \\
\hline$D$ & $29.5 \mathrm{~m}$ \\
\hline Natural Frequency of whipping & $0.463 \mathrm{~Hz}$ \\
& $(2.91 \mathrm{rad} / \mathrm{sec})$ \\
\hline Ship speed & $9.10 \mathrm{~m} / \mathrm{s}$ \\
\hline Specific gravity of water & 1.025 \\
\hline Time step & $0.075 \mathrm{sec}$ \\
\hline Significant wave height & $5 \mathrm{~m}$ \\
\hline Mean wave period & $15 \mathrm{sec}$ \\
\hline
\end{tabular}

\subsection{Modeling of linear generator}

The linear generator is composed of the piston of predetermined mass fitted with permanent magnets which is connected to the hull structure through springs, and the casing fitted with stators fixed to the hull structure, see Fig. 3. When the hull whipping happens, the stators remain relatively static with the hull, while the piston has a relative motion with the stator, which leads to the generation of electric power.

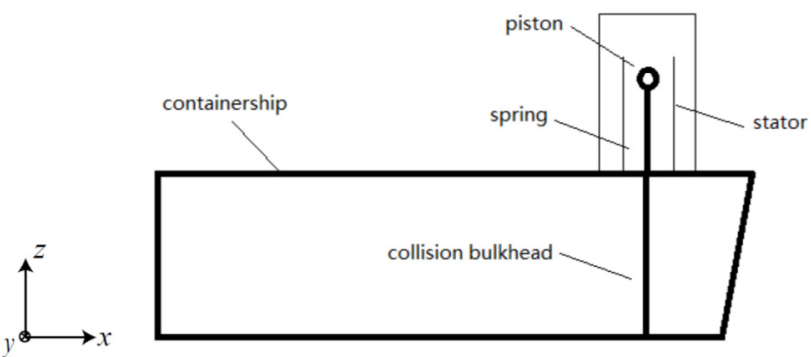

Fig. 3: Modeling of the linear generator on board the ship

The core part of the whipping energy converter can be simplified to a mass-spring system which is simulated by two beam elements as shown in Fig. 4. Element 30001 is the spring element and element 30002 is the mass (piston) element. Node 8924 is the foundation of the whole device which is located on the top of the collision bulkhead. In order to ensure the enough degrees of freedom of the bottom of the spring, the node 8924 , beam element 30000 is created between the node 8924 and the node 8926. According to the symmetry condition about the centerline, the degrees of freedom of the translation to the $y$ direction, rotation around $x$-axis and $z$-axis of node 20000 and node 20001 are constrained, where $x$ is the hull longitudinal axis, $y$ is the transverse axis and $z$ is the vertical axis. The device position in the FE model is shown in Fig. 5.

To optimize the function of power generation as well as to function as a dynamic damper, it is essential that the mass-spring system of the whipping energy converter is resonant with the whipping frequency. Therefore, the natural frequency of the mass-spring system should be designed to identical to the whipping frequency, i.e. $2.91 \mathrm{rad} / \mathrm{sec}$. Given the natural frequency of the whipping energy converter, $\omega_{0}$, is obtained by Eq. 1 ,

$$
\omega_{0}=\sqrt{\frac{k_{0}}{m_{0}}}=2.91 \mathrm{rad} / \mathrm{s}
$$

where $k_{0}$ is the spring constant, and $m_{0}$ is the mass of the piston, then, the relationship between $k_{0}$ and $m_{0}$ is obtained as Eq. 2 .

$$
k_{0}=8.4681 m_{0}
$$

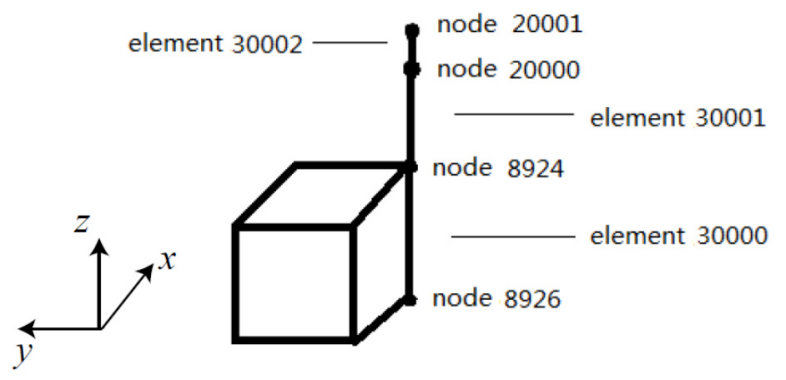

Fig. 4: FE model of whipping energy converter

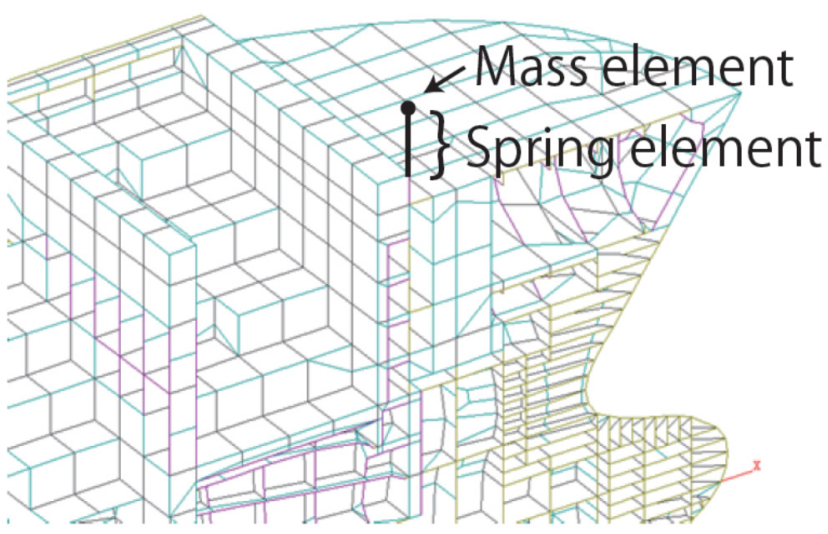

Fig. 5: Whipping energy converter location in FE model

In order to create a standard model, the spring constant $k_{0}$ was first determined to be $40 \mathrm{kN} / \mathrm{m}$ as a practicable figure. Then, $m_{0}$ is obtained from Eq. 2 to be $4720 \mathrm{~kg}$. The element properties in the FE model were determined assuming the length of the spring $l_{0}=$ $2000 \mathrm{~mm}$ and the length of the piston element $l_{m}=10 \mathrm{~mm}$. Then, to achieve the spring constant $k_{0}$ of $40 \mathrm{kN} / \mathrm{m}$, the sectional area of the spring element is obtained from Eq. 3, where $E$ denotes Young's modulus.

$$
A_{0}=\frac{k_{0} l_{0}}{E}
$$

To achieve the target mass of $m_{0}=4720 \mathrm{~kg}$ in the piston element, the product of the sectional area $A_{m}$ and the density $\rho$ should be calculated from Eq. 4 .

$$
A_{m} \rho=\frac{m_{0}}{l_{m}}
$$

Thus, the element properties given in the spring element and the piston element are summarized in Table 2.

When we consider the actual application of this power generation device, damping of the mass motion depends on the magnitude of power generated from the motion. However, at this moment, the actual device is not designed, and the damping is unknown. Therefore, we used the same Rayleigh damping for this 
device as applied to the hull structures explained in Section 2.1.

Table 2 Element properties of the standard mass-spring model

\begin{tabular}{|c|c|c|c|}
\hline \multicolumn{2}{|c|}{ Spring element } & \multicolumn{2}{|c|}{ Piston element } \\
\hline$k_{0}$ & $40 \mathrm{kN} / \mathrm{m}$ & $m_{0}$ & $4720 \mathrm{~kg}$ \\
\hline$l_{0}$ & $2000 \mathrm{~mm}$ & $l_{\mathrm{m}}$ & $10 \mathrm{~mm}$ \\
\hline$A_{0}$ & $0.389 \mathrm{~mm}^{2}$ & $A_{\mathrm{m}}$ & $12800 \mathrm{~mm}^{2}$ \\
\hline$E$ & $206 \mathrm{kN} / \mathrm{mm}^{2}$ & $\rho$ & $3.6875 \times 10^{-2}$ \\
\hline
\end{tabular}

\section{Simulation results and parametric analysis}

\subsection{Analysis of the standard model}

Firstly, analysis results of a container ship fitted with the standard whipping energy converter model (standard model) are compared with the results of the model without whipping energy converter (original model). Fig. 6 shows the time series of the dynamic component of midship hatch coaming top longitudinal stress of the original model, while Fig. 7 shows the time series of the dynamic component of the stress of the standard model at the same location. Fig. 8 and Fig. 9 are the time series of the vertical displacement of the bottom of the spring fixed on the board (node 8924) of the original model and the standard model, respectively. The vertical displacement is the elastic deflection excluding the component of ship motion. The relative displacement between the mass and the bottom of the spring, namely between the node 20000 and the node 8924 of the standard model has been calculated in Fig.10.

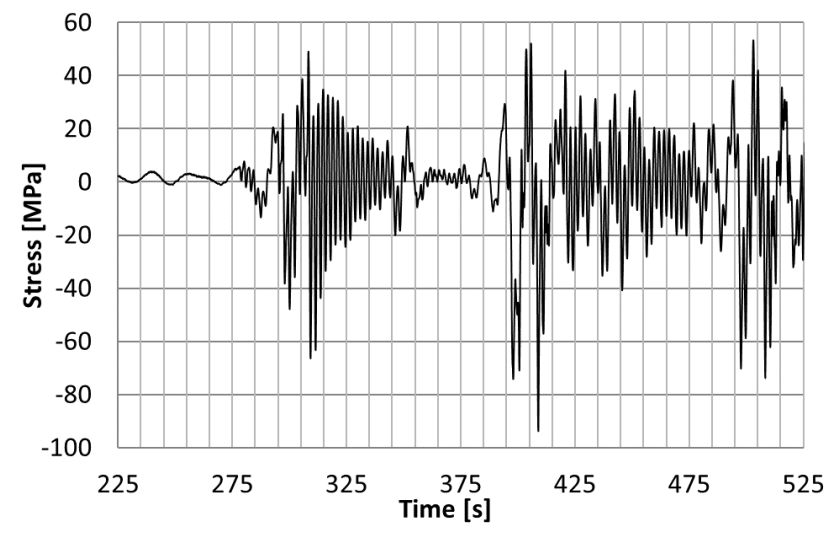

Fig. 6: Midship hatch coaming top stress of the original model

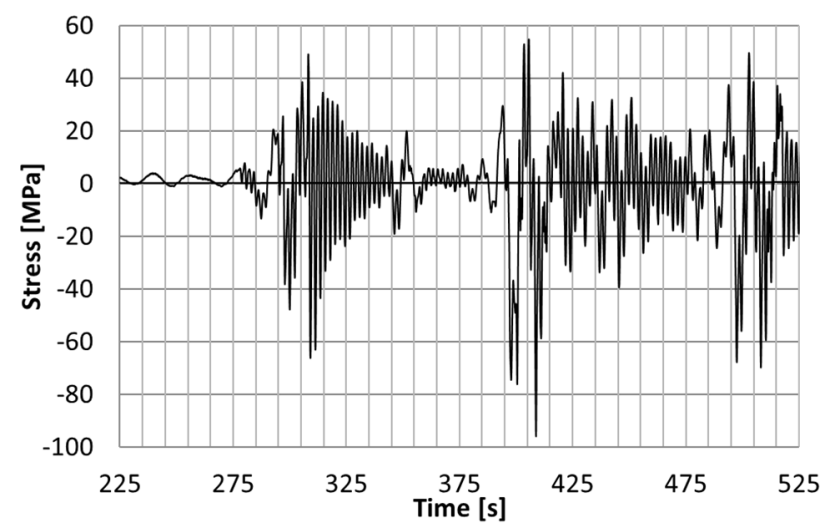

Fig. 7: Midship hatch coaming top stress of the standard model
From these time series of the responses, we can clearly observe high frequency whipping response components superimposed on the low frequency wave induced response components. From the comparison between the original model and the standard model, no significant differences are observed.

We can observe in Figs. 8 and 9 that there is a long period drift of the mean value of the vertical displacement of the linear generator base. This drift is a rigid body motion of the FE model, and is considered to have been caused by accumulation of small magnitude of numerical errors. This drift does not affect the elastic response of the hull structure, as we can see no drift of the mean value of midship bending stresses in Figs. 6 and 7 .

From Fig. 10, we can observe that the relative displacement is much larger than the displacement at the base of the spring by nearly ten times. This means that the whipping vibration at the base of the spring produces sufficiently amplified vibration at the top of the spring. In addition, the amplified large vibration amplitude is sustained for a long period, compared with the swift damping of the whipping responses. The wave component barely existed in the relative displacement results. From these results, we can expect high power generating performance of the system.

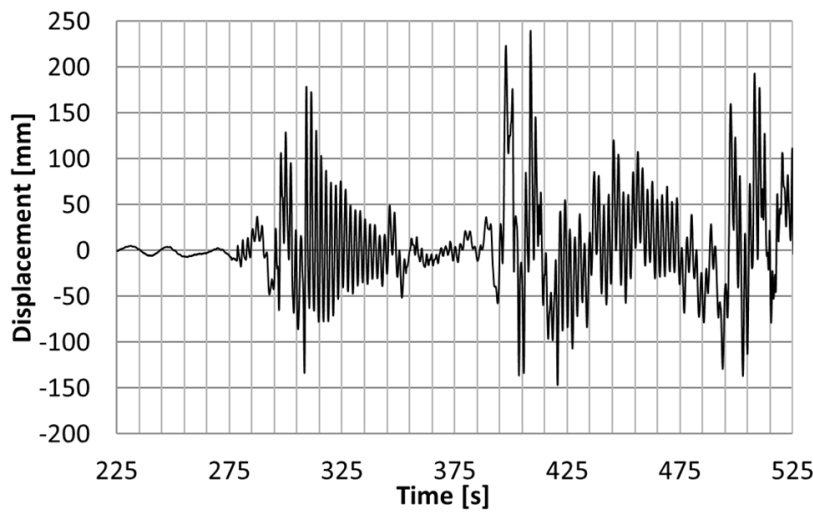

Fig. 8: Vertical displacement of the linear generator base of the original model

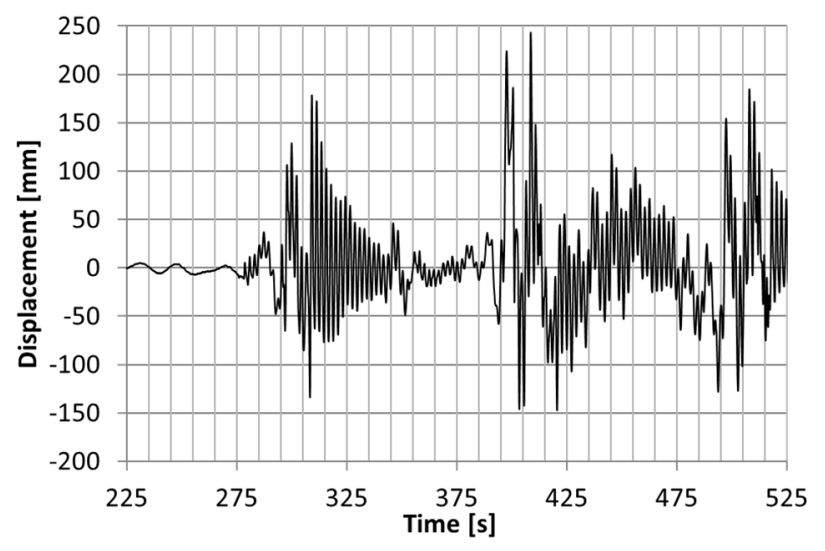

Fig. 9: Vertical displacement of the linear generator base of the standard model 


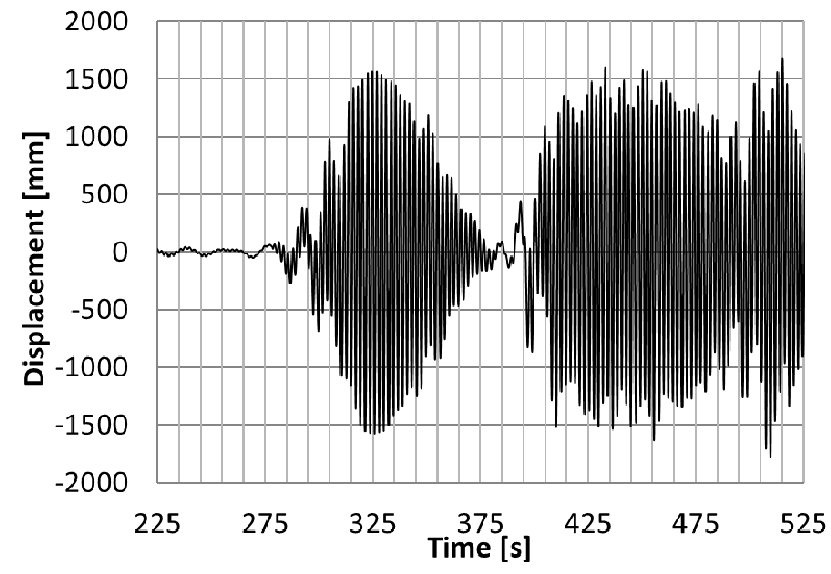

Fig. 10: Relative displacement between the mass and board of the standard model

In order to facilitate the further comparison, the fast Fourier transformation (FFT) was used to transform the time domain results into frequency domain results, as shown in Fig. 11, Fig. 12 and Fig. 13. From Fig. 11 and Fig. 12, we can observe two main peaks. The first peak at around $0.09 \mathrm{~Hz}$ is the wave induced response, and the second peak at around $0.46 \mathrm{~Hz}$ is the whipping response. The leftmost peak around $0.01 \sim 0.02 \mathrm{~Hz}$ in Fig. 12 is the result of the rigid body drift of the FE model, and therefore is to be ignored. The peak value of the whipping response is reduced due to the fitting of the whipping energy converter, implying that the whipping energy converter functions as a dynamic damper. From Fig. 13, relative displacement due to the whipping response is significant, while relative displacement due to wave becomes almost invisible.

The results as obtained in Fig. 6 through Fig. 13 are based on the assumed damping coefficient of the mass motion of the device. They may change according to the damping due to the magnitude of the generated power.

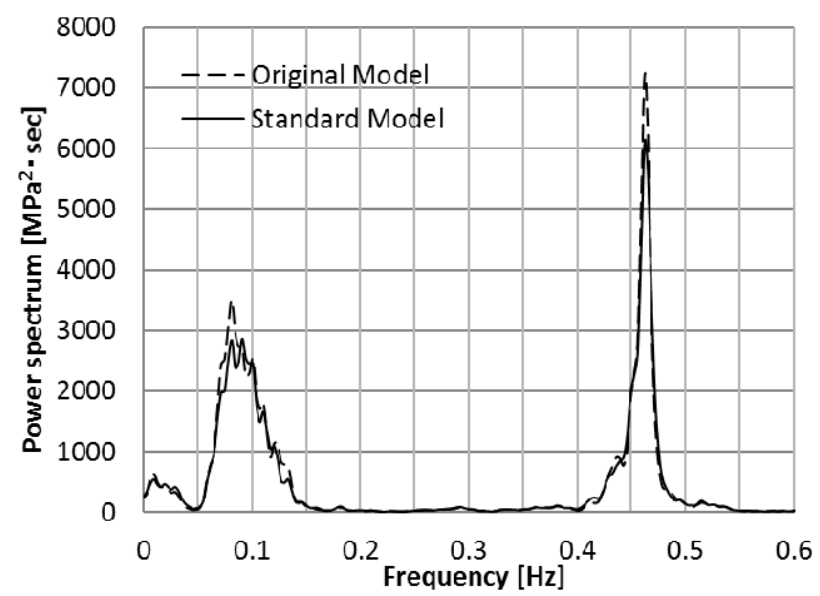

Fig. 11: Power spectrum of midship longitudinal stress

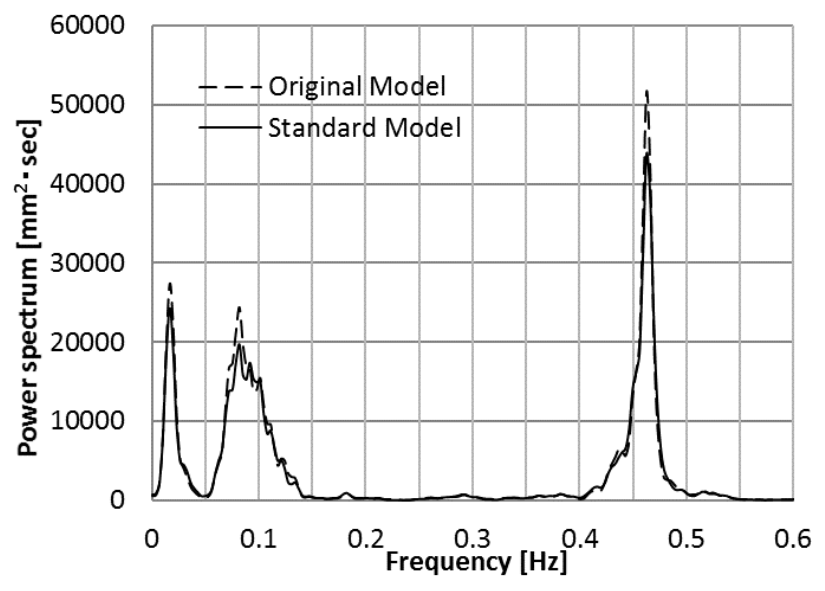

Fig. 12: Power spectrum of vertical displacement of the linear generator base

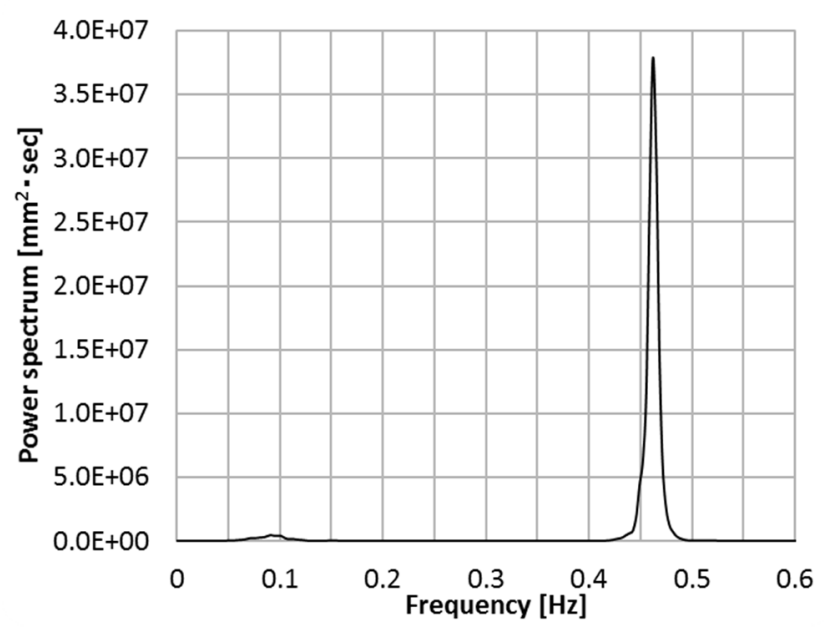

Fig. 13: Power spectrum of relative displacement between the mass and board

\subsection{Parametric analysis}

In order to make full use of this device to get more energy and reduce the impact of hull whipping at the same time, it is necessary to study the working conditions and relative parameters of the device. Therefore, in this section we discuss three factors, which were resonance condition, device position and weight of the piston, and their effect on the whipping energy converter. Model groups and relative parameters are summarized in Table 3. The Model ID "X_YYYY(ZZZZ)" is named after the following rule. " $\mathrm{X}$ " denotes the resonance condition of the whipping energy converter. " $R$ " in place of " $X$ " means that the whipping energy converter is resonant to the whipping frequency. "HF" means that natural frequency of the whipping energy converter is higher than the whipping frequency. "LF" means the opposite condition. "YYYY" denotes the mass of the piston in kg. "MID" and "AFT" in place of "ZZZ" means that the whipping energy converter is located at midship and aft part, respectively. Otherwise the whipping energy converter is located at the bow of the ship. The model R_4720 is the standard model, discussed in section 2.1. 
Table 3 Model groups and parameters

\begin{tabular}{|c|c|c|c|c|}
\hline Model ID & $\begin{array}{c}k \\
{[\mathrm{kN} / \mathrm{m}]}\end{array}$ & $\begin{array}{c}m \\
{[\mathrm{~kg}]}\end{array}$ & $\begin{array}{c}\text { Nat.Freq. } \\
{[\mathrm{Hz}]}\end{array}$ & location \\
\hline R_4720 & 40 & 4720 & 0.463 & bow \\
\hline HF_2360 & 40 & 2360 & 0.655 & bow \\
\hline LF_9440 & 40 & 9440 & 0.328 & bow \\
\hline R_236 & 2 & 236 & 0.463 & bow \\
\hline R_1180 & 10 & 1180 & 0.463 & bow \\
\hline R_94440 & 80 & 9440 & 0.463 & bow \\
\hline R_94400 & 800 & 94400 & 0.463 & bow \\
\hline R_4720_MID & \multicolumn{5}{|c|}{ Same to model R_4720 } & midship \\
\hline R_4720_AFT & \multicolumn{6}{|c}{ Same to model R_4720 } & aft \\
\hline
\end{tabular}

Analysis results of the two cases with different natural frequencies, model HF_2360 and LF_9440, are shown from Fig. 14 to Fig. 19. From comparison between Fig. 14 and Fig. 11, the spectrum peak of the whipping frequency is almost identical among HF_2360, LF_9440 and the original model, while substantial reduction in the peak is observed for the standard model, R_4720. Fig. 15 shows the relative displacement between the mass and board. Contrary to the response of model R_4720, the responses at the whipping frequency of HF_2360 and LF_ 9440 are very small and invisible in the figure. Fig. 16 and Fig. 17 show the enlarged power spectrum of HF_2360 and LF_9440, respectively. In addition to the wave frequency response around $0.09 \mathrm{~Hz}$ and whipping frequency response around $0.46 \mathrm{~Hz}$, response around $0.66 \mathrm{~Hz}$ becomes also prominent in case of HF_2360, while response around $0.33 \mathrm{~Hz}$ becomes prominent in case of LF_9440. According to Table 3, these frequencies correspond to the natural frequencies of each whipping energy converter system.

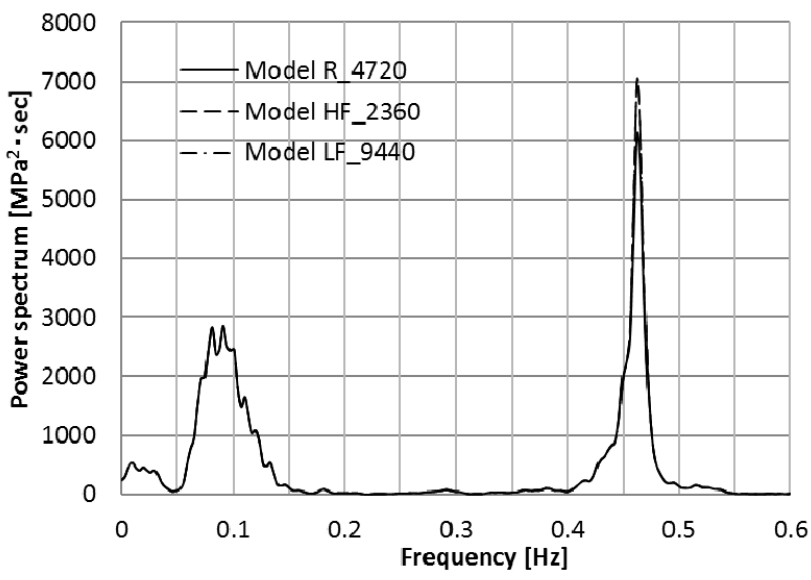

Fig. 14: Power spectrum of midship longitudinal stress with whipping energy converter of different natural frequencies

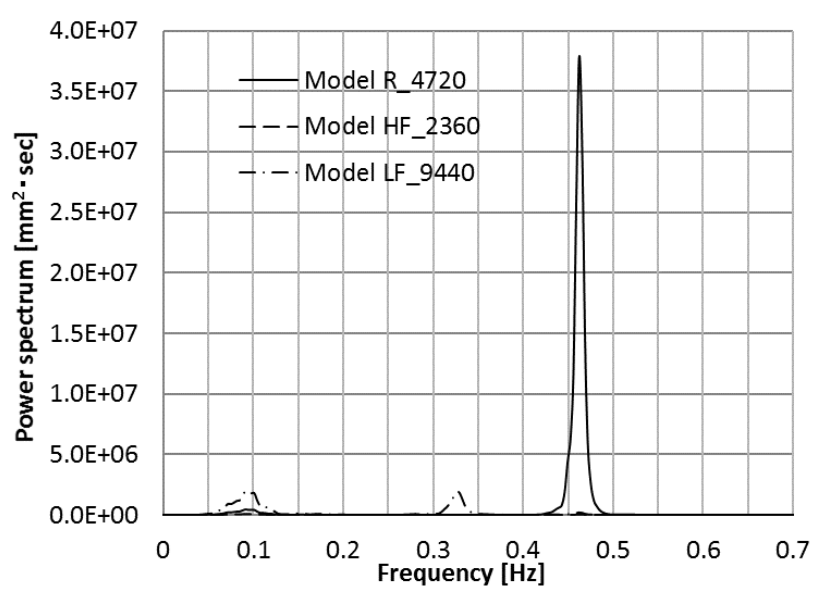

Fig. 15: Power spectrum of relative displacement with whipping energy converter of different natural frequencies

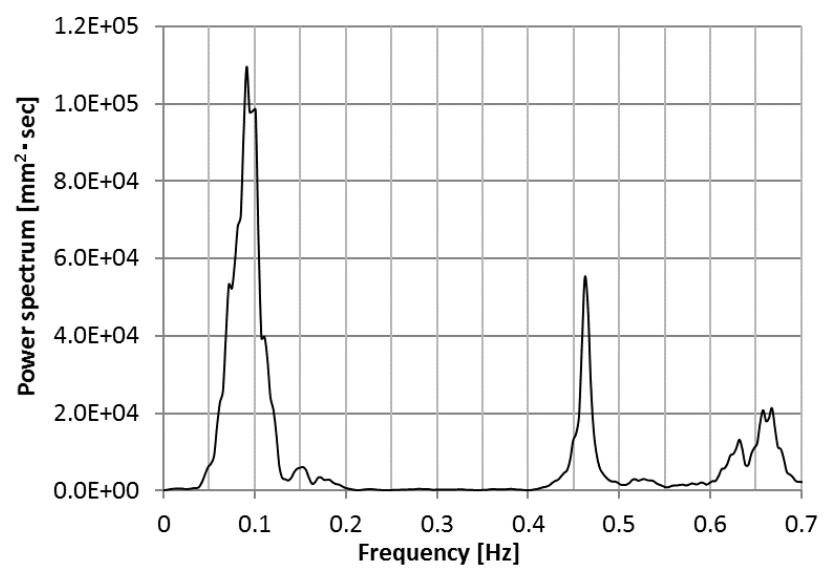

Fig. 16: Power spectrum of relative displacement of HF_2360

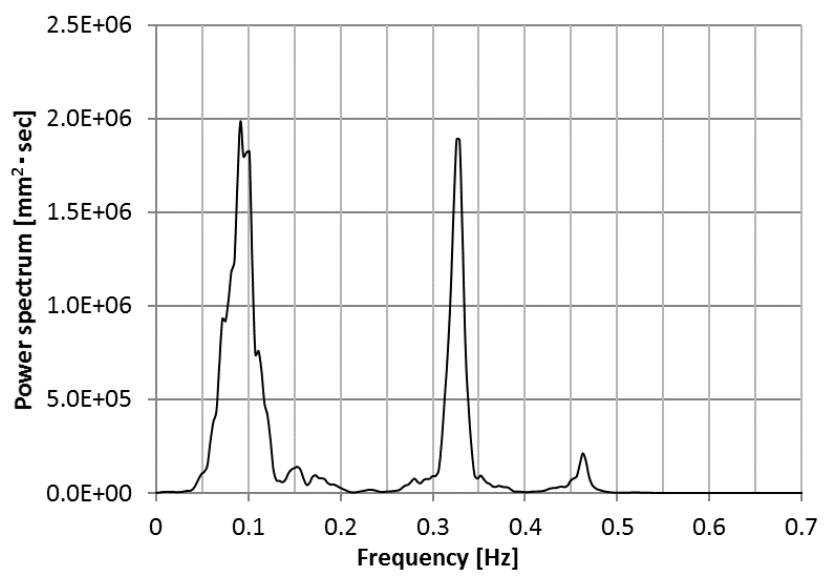

Fig. 17: Power spectrum of relative displacement of LF_9440

Fig. 18 shows time series of the vertical displacement at the base of the spring and at the mass in case of HF_2360. The time series are high-pass filtered with cut-off frequency of $0.3 \mathrm{~Hz}$, in order to compare the whipping responses only. We can see that the mass vibrates in a similar manner with the base in the same phase. Fig. 19 shows the same time series in case of LF_ 9440. We can observe that the dominant frequency of the mass vibration is lower than the exciting frequency, corresponding to the natural frequency of the mass-spring system when the mass is 
heavier.

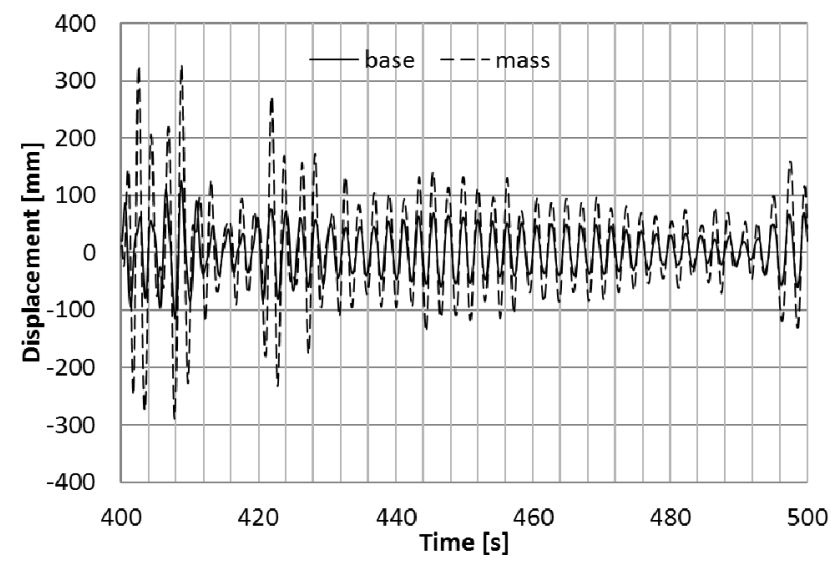

Fig. 18: Time series of mass and base vertical displacement of HF 2360

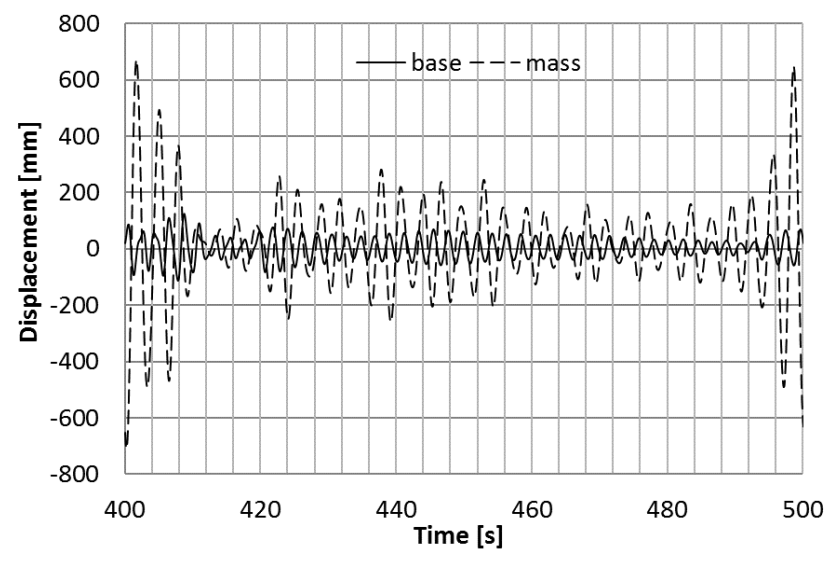

Fig. 19: Time series of mass and base vertical displacement of LF 9440

Models R_236, R_1180, R_9440 and R_94400 belong to the group with same natural frequency as $R_{-} 4720$ with different amount of weight of the mass. Model R_236 and R_94400 have extremely light and heavy mass, while model R 1180 and R_9440 have moderately light and heavy mass, respectively. Fig. 20 and Fig. 21 show power spectrum of longitudinal stress and relative displacement of models R_1180 and R_9440 compared with the standard model, R_4720. Fig. 22 and Fig. 23 show those of models R_236 and R_94400. Fig. 20 and Fig. 21 show that under the resonance condition, when the piston weight becomes larger, the hull whipping stress becomes smaller, which leads to the decrease of whipping responses. In addition, the increase of piston weight would also lead to the decrease of relative displacement.

The rule reflected by the results of Fig. 22 and Fig. 23 was as same as those in Fig. 20 and Fig. 21, but the reduction in whipping response in case of extremely heavy weight of mass (R_94400) was much more prominent. In addition, the shape of the spectrum around the whipping frequency part of Model R_94400 in Fig. 22 and Fig. 23 had two peaks. This was because when the piston weight increased to nearly or over $1 / 2000$ of the ship displacement, the whipping energy converter effectively functioned as a dynamic damper, dividing the natural frequency into two coupled natural frequencies.

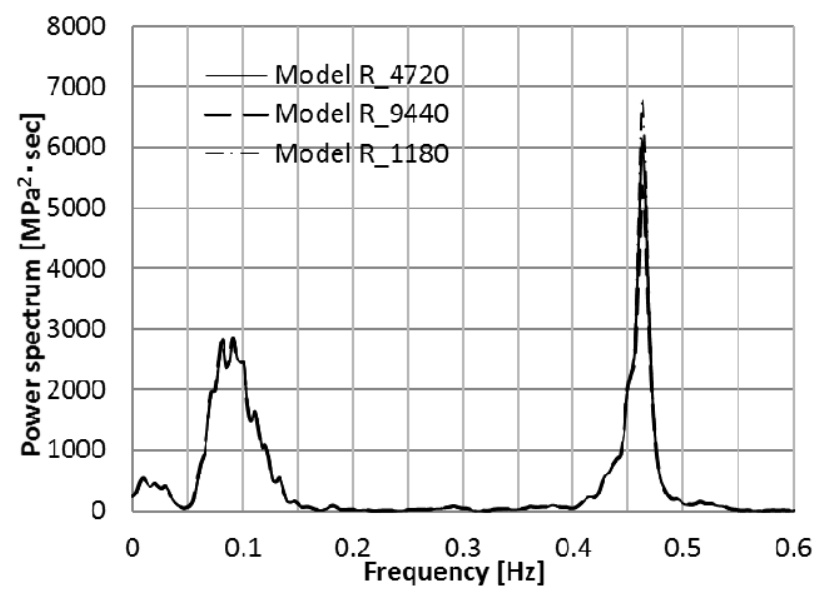

Fig. 20: Power spectrum of midship longitudinal stress among models R_4720, R_9440 and R_1180

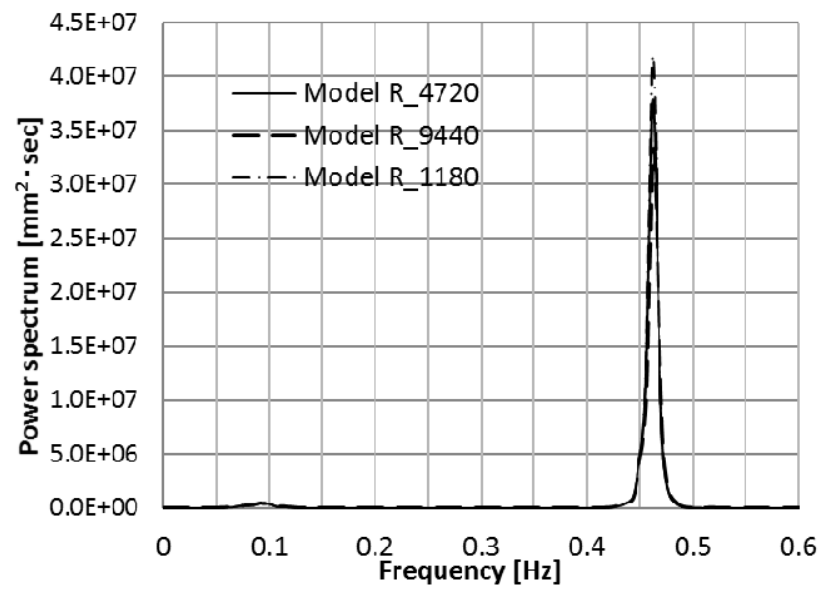

Fig. 21: Power spectrum of relative displacement among models R_4720, R_9440 and R_1180

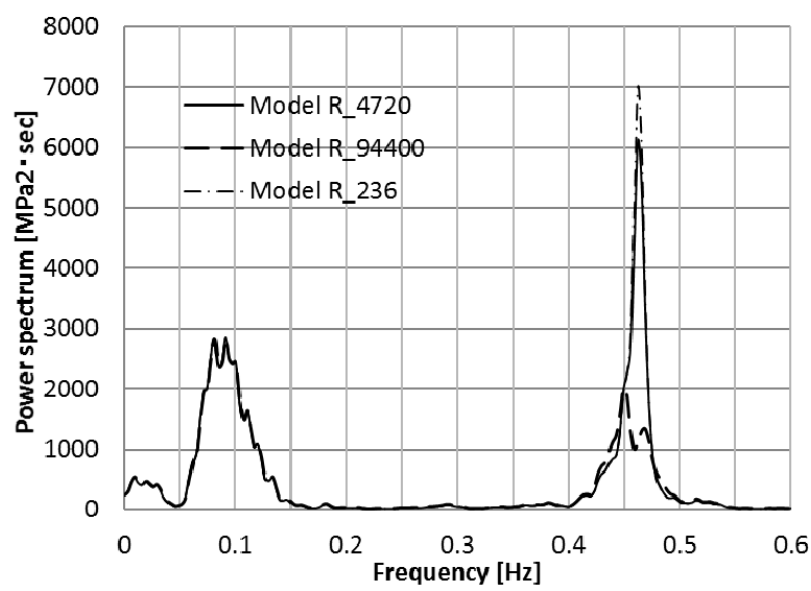

Fig. 22: Power spectrum of midship longitudinal stress among models R_4720, R_94400 and R_236

Fig. 24 shows the comparison of a time series of midship longitudinal stress during a certain period between models R 4720 and R 94400, that is, models with moderate weight and extremely heavy weight of mass under resonant condition. We can observe from this figure that the first largest stress amplitude induced by the heavy slamming has almost same value between R_4270 and R_94400 (see the time of around $70 \mathrm{~s}$ in the figure), 
while the subsequent damping is much more significant and the response diminishes more rapidly in R_94400 than in R_4720. Therefore, the significant reduction of the spectrum peak in Fig. 22 was not caused by the decrease in the largest stress amplitude, but was caused by the substantial decrease in the subsequent vibrational responses due to the larger dynamic damping effect. This implies that the installation of the whipping energy converter may reduce the repetitive stresses and contribute to the enhancement of fatigue strength, but may not be effective to reduce the first largest whipping vibration amplitude, which affect the ultimate strength of the hull girder.

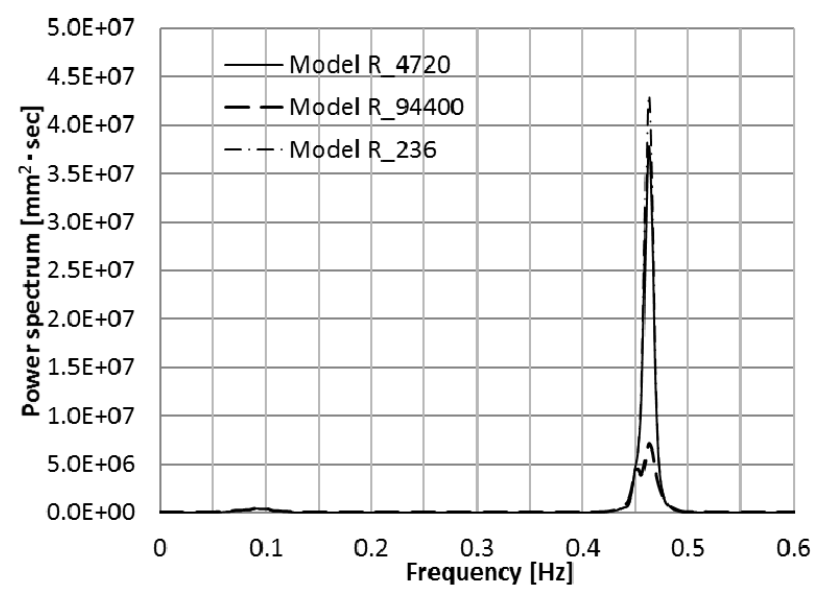

Fig. 23: Power spectrum of relative displacement among models R_4720, R_94400 and R_236

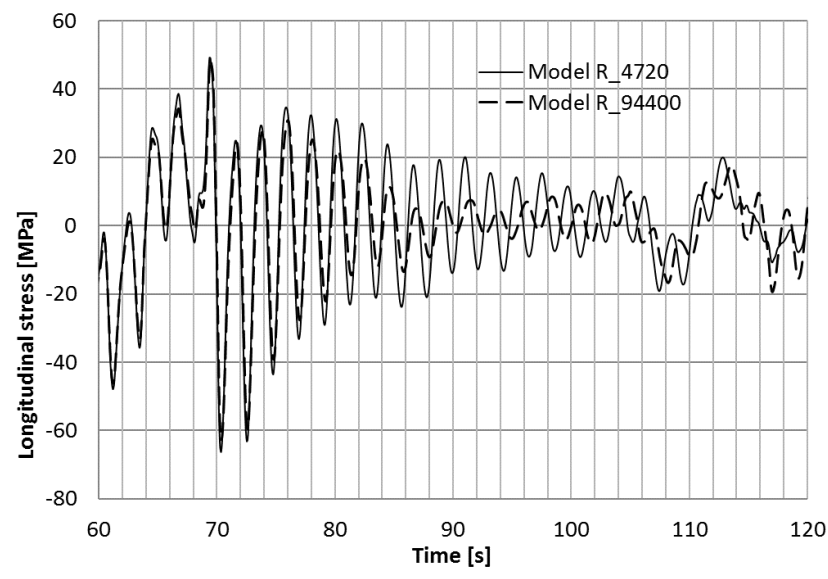

Fig. 24: Comparison of time series of midship longitudinal stress between R_4720 and R_94400

The models R_4720_MID and R_4720_AFT belong to the device position experimental group. The device location in Model R_4720_MID is on the top of the midship bulkhead. The device location in Model R_4720_AFT is on the top of the stern bulkhead. Their comparison results are shown in Fig. 25 and Fig. 26. In Fig. 25, frequency range of $0.4 \mathrm{~Hz} \sim 0.5 \mathrm{~Hz}$ is plotted to make the differences visible.

The Fig. 25 and Fig. 26 show that the reduction effect of hull whipping could be expressed as bow $>$ stern $>$ midship and the relative displacement could be expressed as bow $>$ stern $>>$ midship, when the whipping energy converters had the same piston weight under the resonance condition. The results indicated that the hull whipping amplitude of midship was smaller than that of bow and stern. Therefore, it was not very useful to set the whipping energy converter on the midship. In the case of the large container ship in our paper, it was better to set the device on the bow. This will be discussed in more detail in Chapter 4 in relation to the amount of power generation, using the observation of whipping natural vibrational mode.

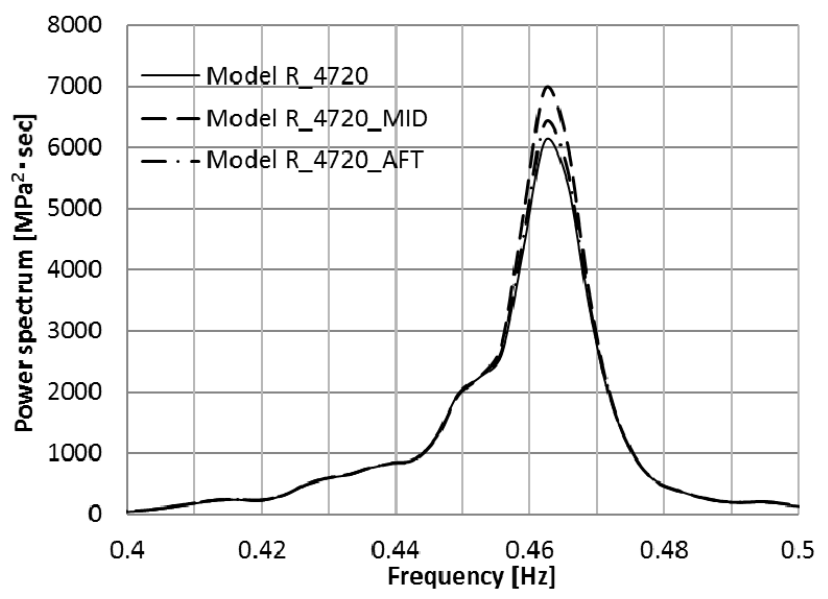

Fig. 25: Power spectrum of midship longitudinal stress with different fitting locations

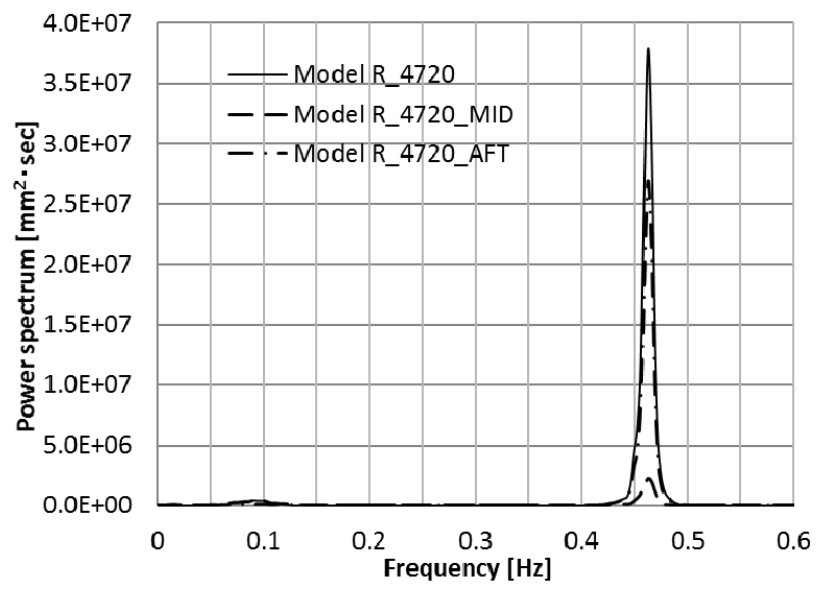

Fig. 26: Power spectrum of relative displacement with different fitting locations

\section{Preliminary discussion on the energy output}

The linear generator itself is not designed in this paper, therefore, the power generated by the system cannot be calculated. However, in this chapter, as a preliminary study on the estimated power generation of the system, we conducted relative comparison of the generated power among the models explained in chapter 3 . Damping of the piston motion due to the electromagnetic force, and any electric and mechanical losses are ignored in this study.

The average induced electromotive force of the whipping energy converter can be calculated by the following formula.

$$
\bar{U}=B_{M} L_{C} \bar{v}
$$

where $\bar{U}$ is the average induced electromotive force in the duration, $B_{M}$ is the magnetic flux density, $L_{C}$ is the coil length, and $\bar{v}$ is the average velocity of the relative motion between the piston and the stator.

As the piston weight is larger and heavier, the permanent 
magnet can be made stronger, and the coil can be made longer. Therefore, we assume that $B_{M} L_{C}$ is proportional to the piston mass $m$ as shown in Eq. 6 .

$$
B_{M} L_{C}=k_{1} m
$$

where $k_{1}$ is the proportional constant.

Average relative velocity between the piston and the stator can be expressed as shown in Eq. 7 .

$$
\bar{v}=\omega \bar{d}
$$

where $\omega$ is the dominant frequency of the relative vibratory displacment $(\mathrm{rad} / \mathrm{s})$, and $\bar{d}$ is the average relative displacement within the simulation duration period of 5 minutes.

We also assume that the average electric power is proportional to the average induced electromotive force, supposing that the resistance increases according to the mass, therefore,

$$
\bar{P}=k_{2} \bar{U}
$$

where $\bar{P}$ is the average electric power, and $k_{2}$ is the proportional constant.

Substituting Eq. 5, Eq. 6 and Eq. 7 into Eq.8, we can obtain

$$
\bar{P}=k_{1} k_{2} \omega m \bar{d}
$$

Therefore, the power generated from the whipping energy converter is assumed to be proportional to the product of the frequency, the piston weight and the relative displacement.

For relative comparison, $\omega m \bar{d}$ of each model is calculated in Table 4, and is plotted in Fig. 27 in logarithmic scale, taking $\log _{10} m$ in the horizontal axis.

Within the resonance group, the power generation becomes greater as the weight of the mass increases as shown in the rising diagonal stroke from bottom left to top right in Fig. 27. As shown in Table 4, although $\bar{d}$ slightly decreases as the mass increases, but the increase in $m$ affected the power generation more efficiently. From the comparison among the fitting location group, the device can generate the largest power at bow, and a little less at stern, and the least power at midship. This may be attributed to the difference in vertical displacement amplitude due to whipping at each location. Fig. 28 shows the two-node vibrational mode of the ship. In this mode, when the vertical displacement at the bow location (node 8924) is normalized to be 1.0 , the vertical displacement at the aft location was 0.932 , and the vertical displacement at the mid location was 0.389 . We can observe that larger vertical vibrational amplitude of the hull causes larger power generation.

In the non-resonant conditions, the generated power significantly decreases. For example, the piston weight in non-resonance model HF_2360 is ten times larger than resonance model R_236, but the power generated from model HF_2360 is smaller than model R_236. The shift to higher frequency looks more disadvantageous than the shift to lower frequency. One reason for this may be the difference in mass weight between the models LF_9440 and HF_2360.
Table 4 Comparison of power generation of each model

\begin{tabular}{|c|c|c|c|c|c|}
\hline Model ID & $\begin{array}{c}m \\
{[\mathrm{~kg}]}\end{array}$ & $\begin{array}{c}\bar{d} \\
{[\mathrm{~m}]}\end{array}$ & $\begin{array}{c}\omega \\
{[\mathrm{rad} / \mathrm{s}]}\end{array}$ & $\omega m \bar{d}$ & Rank \\
\hline R_4720 & 4720 & 0.5307 & 2.91 & 7289 & 3 \\
\hline HF_2360 & 2360 & 0.05424 & 2.91 & 372 & 9 \\
\hline LF_9440 & 9440 & 0.2386 & 2.06 & 4640 & 5 \\
\hline R_236 & 236 & 0.5595 & 2.91 & 384 & 8 \\
\hline R_1180 & 1180 & 0.5527 & 2.91 & 1898 & 7 \\
\hline R_9440 & 9440 & 0.5046 & 2,91 & 13862 & 2 \\
\hline R_94400 & 94400 & 0.3135 & 2.91 & 86120 & 1 \\
\hline R_4720_MID & 4720 & 0.1734 & 2.91 & 2382 & 6 \\
\hline R_4720_AFT & 4720 & 0.4415 & 2.91 & 6064 & 4 \\
\hline
\end{tabular}

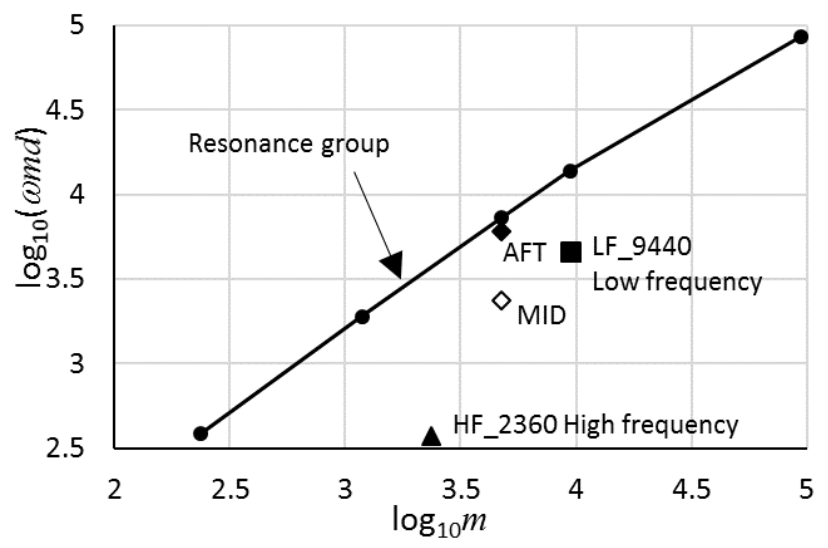

Fig. 27: Comparison of power generation

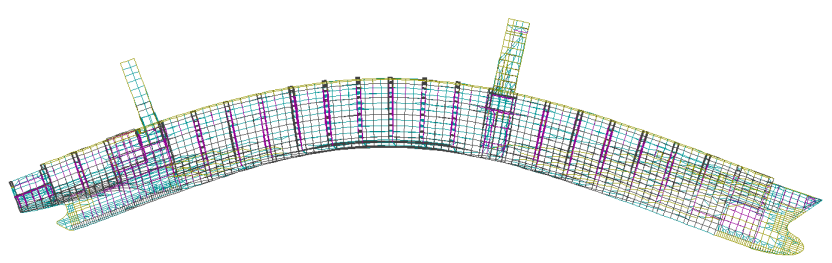

Fig. 28: Two-node vibrational mode $(0.463 \mathrm{~Hz})$

Although the actual linear generator itself is not designed in this study, an example design can be found in e.g. a patent of a wave power generator [12], where mass of $200 \mathrm{~kg}$ is supported by air spring of $7899 \mathrm{~N} / \mathrm{m}$ with coil length of $1000 \mathrm{~m}$, resistance of $10 \Omega$, magnetic flux density of $0.1 \mathrm{~T}$. In this case, it is stated that the power of $1 \mathrm{~kW}$ can be generated when the average relative velocity is $1.0 \mathrm{~m} / \mathrm{s}$. Using this assumption, preliminary rough estimation of generated power in case of R_ $94400, \bar{P}_{R_{-} 94400}$, can be obtained as follows, which shows the feasibility of practical usefulness of this device.

$$
\begin{aligned}
& \bar{v}=\omega \bar{d}=2.91 \times 0.3135=0.9123 \mathrm{~m} / \mathrm{s} \\
& \bar{P}_{R_{-} 94400}=1 \mathrm{~kW} \times \frac{94400}{200} \times \frac{0.9123}{1.0}=431 \mathrm{~kW}
\end{aligned}
$$

Although this is a very preliminary rough estimation, it is considered that trial design of the linear generator device and more accurate estimation of power generation is an important future task.

\section{Concluding remarks}

In this paper, the authors proposed a whipping energy converter, which utilizes a linear generator designed to be resonant to whipping responses of a ship. Numerical simulation of the 
responses of the whipping energy converter was carried out under irregular head sea condition, using time domain ship motion analysis by Rankine source method and subsequent 3-dimensional whole ship FE analysis, and the main parameters of the whipping energy converter was studied. As a result, the following concluding remarks can be made:

1. Whipping and springing responses are basically single-frequency, and more or less constant whipping and springing responses are expected in large container ships in real seas. Therefore, the whipping energy converter can make the most of such advantages for effective power generation.

2. The whipping energy converter also functions as a dynamic damper. With the piston weight of $5 \sim 10$ tons, the whipping vibration is visibly reduced, while if the piston weight is about 100 tons, the spectral peak is reduced to less than one-third.

3. However, the whipping energy converter does not contribute to the reduction of the first largest whipping vibration amplitude, but contributes to the damping of the subsequent repetitive responses. Therefore, the device may be effective to fatigue strength, but not effective to ultimate strength of the hull girder.

4. Larger power generation can be expected as the piston weight is heavier. Bow is the most effective location for this device because of the largest vertical vibrational amplitude of the hull due to whipping.

As important future tasks, the following issued are noted.

1. Because of the huge demand of computing resources of the system, results of only 5-minute simulation were available in this study. Because this duration period of the simulation is considered to be insufficient to obtain statistically significant results, it is an important future task to carry out simulation with longer duration.

2. In this study, the actual linear generator itself is not designed and only preliminary rough estimation is made with regard to the magnitude of power generation. To proceed to the next stage, it is necessary to design the generator and make more accurate estimation of power generation in the actual seas.

3. Damping of the mass motion depends on the magnitude of power generated from the motion. Optimum balance between the damping for the vibration reduction and the power generation is not investigated in the present study, and should be one of the future tasks to be clarified.

\section{References}

1. Falcao A F de O (2010) Wave energy utilization: A review of the technologies, Renewable and Sustainable Energy Reviews 14:899-918

2. Washio Y, Osawa H, Ogata T, Nakagawa H, Okayama S, Nagata Y (2001) A study on characteristics of generated output of the offshore floating type wave power device
"Mighty Whale", Journal of the Society of Naval Architects of Japan, Vol.190, pp.395-405 (in Japanese)

3. Ivanova I A, Bernhoff H, Agren O, Leijon M (2005) Simulated generator for wave energy extraction in deep water, Ocean Engineering 32:1664-1678

4. Gao Y, Shao S, Zou H, Tang M, Xu H, Tian C (2016) A fully floating system for a wave energy converter with direct-driven linear generator, Energy 95:99-109

5. Minoura M, Inoue K, Yoshida H, Tanaka H (2014) Study on recovery of ship motion energy by utilizing linear generator, Conference Proceedings of the Japan Society of Naval Architects and Ocean Engineers, No.19, pp.515-518 (in Japanese)

6. Okada T, Takeda Y, Maeda T (2006) On board measurement of stresses and deflections of a post-panamax containership and its feedback to rational design, Marine Structures 19:141-172

7. Toyoda M, Okada T, Maeda T, Matsumoto T (2008) Full scale measurement of stress and deflections of post-panamax container ship, Design and Operation of Container Ships, London, RINA, 2008

8. Kobayakawa H, Okada T, Kusumoto H, Nagashima T, Neki I (2015) Strength evaluation of containerships based on dynamic elastic response calculation of hull girder, $1^{\text {st }}$ report - Unsteady time domain analysis of ship motions in head seas, Journal of the Japan Society of Naval Architects and Ocean Engineers, No.22, pp.161-173 (in Japanese)

9. Kawasaki Y, Okada T, Kobayakawa H, Amaya I, Miyashita T, Nagashima T, Neki I (2016) Influence of hull girder flexibility to whipping response of an ultra large container ship, The $30^{\text {th }}$ Asian-Pacific Technical Exchange and Advisory Meeting on Marine Structures (TEAM 2016), Mokpo, Korea, pp.124-131

10. Kawasaki Y, Okada T, Kobayakawa H, Amaya I, Miyashita T, Nagashima T, Neki I (2017) A study on forced vibration of double bottom structure due to whipping on an ultra large container ship, Proceedings of the ASME $30^{\text {th }}$ International Conference on Ocean, Offshore \& Arctic Engineering (OMAE2017), Trondheim, Norway, Paper No. OMAE2017-61149

11. Kawasaki Y, Okada T, Kobayakawa H, Amaya I, Miyashita T, Nagashima T, Neki I (2017) Strength evaluation of containerships based on dynamic elastic response calculation of hull girder, $2^{\text {nd }}$ report - Influence of hull girder rigidity and correlation between double bottom bending and hull girder bending, Journal of the Japan Society of Naval Architects and Ocean Engineers, No.25, pp.191-203 (in Japanese)

12. Miyajima K, Kitada H (2004) Wave power generator, Patent WO2005040603 A1 